\title{
RESPON PERTUMBUHAN SEMAI MAHONI (Swietenia macrophylla King) PADA POT ORGANIK DAN DIINOKULASI FUNGI MIKORIZA ARBUSKULA (FMA)
}

\author{
Growth Response of Seedling Mahogany (Swietenia macrophylla King) by Arbuscular Mycorrhizal \\ Fungi (AMF) Inoculation on Organic Pot
}

\author{
Sri Wilarso Budi ${ }^{*}$ dan Faradila Mei Jayani ${ }^{2}$
}

(Diterima Februari 2017/Disetujui Juni 2020)

\begin{abstract}
A forest trees seedling production nowadays had used a polybag that caused the roots grow in a circle and the polybag are not easily degraded by the environment. It can be replaced with the use of container based on organic material that is environmentally friendly. The purposes of this study were to analyze the effect of treatment of raw material of organic pot and to analyze the inoculation of AMF to the growth of mahogany seedling as well. This study used the completely randomized design with two factor. The interaction of organic pot composition and the addition of AMF were significantly affected in terms of height and total dry weight of mahogany seedling. A single treatment of organic pot composition gave a significant effect on the increase of mahogany seedling diameter. A single treatment with AMF addition was significantly affected on the increase of both diameter and \% mycorrhizal colonization at the root of mahogany seedling. The best treatment that has the greatest response of mahogany seedlings growth was the organic pot composition of newspaper:compost with a ratio of 3:2 along with the addition of $A M F$.
\end{abstract}

Keywords: Arbuscular Mycorrhizal Fungi (AMF), inoculation, Mahogany (Swietenia macrophylla King), Organic Pot, seedling

\section{PENDAHULUAN}

Kebutuhan bibit tanaman kehutanan saat ini masih tergolong tinggi. Kegiatan seperti rehabilitasi lahan hutan, penghijauan, dan program penanaman satu milyar pohon tentu membutuhkan bibit tanaman kehutanan dalam jumlah yang besar. Menurut Kementerian Perencanaan Pembangunan Nasional (2014) pemerintah menargetkan rehabilitasi lahan kritis seluas 5,5 juta ha yang tertulis dalam Rancangan Awal Rencana Pembangunan Jangka Menengah (RPJM) 2015-2019. Asumsi penanaman dilakukan dengan jarak $4 \times 4$ meter dan penyulaman sebesar $20 \%$ maka kebutuhan bibit secara nasional mencapai 4.125 milyar batang.

Produksi bibit tanaman kehutanan sebagian besar masih menggunakan polybag sebagai tempat media tumbuhnya. Menurut Budi et al. (2012) penggunaan polybag menimbulkan beberapa kerugian yaitu akar tanaman tumbuh melingkar dan plastik tidak mudah terdegradasi oleh lingkungan baik oleh hujan, panas matahari, maupun mikroorganisme yang hidup dalam tanah. Sebagai alternatif dalam mengatasi masalah tersebut maka penggunaan polybag dapat diganti dengan penggunaan wadah semai berbahan dasar organik yang ramah lingkungan. Wadah semai berbahan dasar organik tersebut biasa disebut sebagai pot organik. Pot organik terbuat dari kertas koran bekas yang dicampur dengan kompos atau bahan lain. Keunggulan pot organik yaitu waktu untuk terdekomposisi dengan alam lebih cepat

\footnotetext{
${ }^{1}$ Staf Pengajar Departemen Silvikultur, Fakultas

Kehutanan dan Lingkungan Institut Pertanian Bogor

* Penulis korespondensi:

e-mail:wilarso62@yahoo.com

2 Mahasiswa Departemen Silvikultur, Fakultas Kehutanan Institut Pertanian Bogor
}

dibandingkan dengan polybag. Pot organik juga dapat langsung ditanam ke dalam tanah tanpa harus membuka wadahnya sehingga tidak menyebabkan kerusakan perakaran saat bibit dipindahkan ke lapangan.

Pot organik selain berfungsi sebagai wadah tumbuh diharapkan juga dapat memberikan tambahan unsur hara yang dibutuhkan untuk pertumbuhan tanaman. Salah satu cara untuk meningkatkan unsur hara tersedia bagi pertumbuhan tanaman yaitu mikoriza. Mikoriza merupakan asosiasi simbiotik yang terbentuk antara akar sebagian besar spesies tanaman dan fungi. Menurut Nusantara et al. (2012) manfaat mikoriza yaitu (1) meningkatkan jumlah dan mutu hasil tanaman karena membantu penyerapan unsur hara; (2) mengurangi kebutuhan pupuk dan pestisida; (3) mereduksi emisi $\mathrm{CO}_{2}$; dan (4) menyuburkan tanah. Oleh karena itu perlu dilakukan penelitian untuk mengetahui respon pertumbuhan bibit mahoni ( $S$. macrophylla King) terhadap penggunaan wadah semai berbahan organik (pot organik) dan penambahan mikoriza. Tujuan penelitian ini adalah menganalisis pengaruh perlakuan bahan baku pot organik dan inokulasi Fungi Mikoriza Arbuskula (FMA) terhadap pertumbuhan bibit mahoni (S. macrophylla King).

\section{METODE PENELITIAN}

Waktu dan Lokasi Penelitian

Penelitian dilaksanakan di Persemaian Permanen Dramaga IPB selama 11 bulan dari bulan Mei 2015 sampai dengan April 2016. Penghitungan kolonisasi 
FMA dilakukan di Laboratorium Teknologi Mikoriza dan Kualitas Bibit Departemen Silvikultur Fakultas Kehutanan IPB. Analisis tanah dilakukan di Laboratorium Analisis Tanah Departemen Manajemen Sumberdaya Lahan Fakultas Pertanian IPB.

\section{Alat dan Bahan}

Alat yang digunakan dalam penelitian yaitu alat pencetak pot organik, rak policup, ayakan pasir dan tanah, drum, kompor, wajan, alat penyiram, penggaris, caliper, neraca digital, oven, kamera digital, tallysheet, alat tulis kantor, dan seperangkat komputer.

Bahan yang digunakan dalam penelitian yaitu semai mahoni (S. macrophylla King), koran bekas, kompos, arang tempurung kelapa, inokulum mikoriza, dan topsoil.

\section{Prosedur Penelitian}

Penelitian ini dilaksanakan dengan tahapan-tahapan sebagai berikut:

\section{Persiapan Pot Organik}

Kertas koran dipotong-potong kemudian direndam dalam drum besar berisi air selama 30 hari. Selama perendaman dilakukan pengadukan dan pergantian air. Setelah kertas koran menjadi bubur kemudian diambil untuk dilakukan penyaringan yang berguna untuk mengurangi kadar air.

Pencampuran antara bubur kertas dengan bahan pencampur lain dengan perbandingan sebagai berikut : 1.) bubur kertas koran $100 \%$ (kontrol), 2.) kertas koran + kompos $(3: 2), 3$.) bubur kertas koran + arang tempurung kelapa (3:2), dan 4.) bubur kertas koran + kompos + arang tempurung kelapa $(1: 1: 1)$

Pencetakan dilakukan secara manual dengan menggunakan alat pencetak pot organik. Pot yang telah dicetak diletakkan di atas nampan dengan posisi terbalik. Pot dikeringkan dibawah sinar matahari selama 4 hari.

2. Perkecambahan Mahoni (S. macrophylla King)

Benih mahoni dikecambahkan pada media topsoil dan cocopeat pada bedengan yang ditutupi daun kelapa kering.

3. Pemilihan Semai Mahoni (S. macrophylla King)

Semai yang dipilih yaitu semai mahoni yang berasal dari persemaian permanen dan telah berumur 1 bulan dengan rata-rata tinggi $6 \mathrm{~cm}$.

4. Persiapan Media Sapih

Media sapih yang digunakan yaitu topsoil yang berasal dari Persemaian Permanen Dramaga IPB. Topsoil disangrai selama 1 jam terlebih dahulu agar steril.

5. Penyapihan Semai

Penyapihan dilakukan pada sore hari untuk mengurangi penguapan.

6. Inokulasi Tanaman

Inokulum FMA berupa zeolith yang berisi koloni mikoriza jenis Gigaspora sp. yang disiapkan dengan dosis $18 \mathrm{~g}$ ( \pm setara dengan 50 spora). Inokulasi dilakukan pada saat penyapihan dengan meletakkan inokulum FMA pada lubang tanam.

\section{Pemeliharaan}

Pemeliharaan semai yang telah disapih dilakukan dengan penyiraman 2 kali sehari yaitu setiap pagi dan sore hari dan pembersihan gulma yang tumbuh pada media tanam.

\section{Pengamatan dan Pengambilan Data}

Parameter yang diukur sebelum pemanenan semai yaitu diameter dan tinggi semai mahoni. Pengamatan terhadap diameter dan tinggi dilakukan selama 16 minggu.

\section{Pemanenan dan Pengambilan Data}

Pemanenan dilakukan dengan menghancurkan pot organik kemudian memisahkan tanaman dengan media. Parameter yang diukur setelah pemanenan yaitu kandungan unsur hara pot organik dan media tanam (N, C, P total, dan P tersedia), berat kering total, Nisbah Pucuk Akar (NPA), dan \% kolonisasi mikoriza.

\section{Rancangan Percobaan dan Analisis Data}

Rancangan percobaan yang digunakan yaitu Rancangan Acak Lengkap (RAL) dengan dua faktor. Faktor A merupakan komposisi pot organik dan faktor B merupakan penambahan FMA. Faktor A terdiri atas empat perlakuan dan faktor B terdiri atas dua perlakuan. Setiap perlakuan pada faktor A dikombinasikan dengan perlakuan dari faktor B menjadi AB sehingga terdapat delapan kombinasi. Satu kombinasi terdapat sepuluh ulangan sehingga percobaan dibutuhkan 80 unit pot organik dan semai mahoni.

\section{HASIL DAN PEMBAHASAN}

\section{Pengaruh Interaksi Komposisi Pot Organik dan Penambahan Mikoriza}

Rekapitulasi hasil analisis sidik ragam pengaruh interaksi komposisi pot organik dan penambahan mikoriza terhadap pertumbuhan semai mahoni disajikan pada Tabel 1. Berdasarkan analisis sidik ragam tersebut menunjukkan bahwa perlakuan interaksi komposisi pot organik dan penambahan mikoriza berpengaruh nyata terhadap tinggi dan berat kering total semai mahoni.

Hasil uji Duncan pengaruh interaksi komposisi pot organik dan penambahan mikoriza terhadap pertambahan tinggi semai mahoni disajikan pada Tabel 2 dan hasil uji Duncan pengaruh interaksi komposisi pot organik dan

Tabel 1. Rekapitulasi hasil analisis sidik ragam pengaruh interaksi komposisi pot organik dan penambahan mikoriza terhadap parameter pertumbuhan semai mahoni

\begin{tabular}{|c|c|}
\hline Parameter & Hasil analisis sidik ragam \\
\hline Tinggi & $0.0453 *$ \\
\hline Diameter & $0.9539 \mathrm{tn}$ \\
\hline Berat & $0.0365 *$ \\
\hline Total (BKT) & \\
\hline $\begin{array}{l}\% \quad \text { Kolonisasi } \\
\text { mikoriza }\end{array}$ & $0.6998 \mathrm{tn}$ \\
\hline \multicolumn{2}{|c|}{$\begin{array}{l}\text { Keterangan: } \\
\text { Angka-angka dalam tabel adalah nilai signifikan. } \\
* \quad=\text { perlakuan berpengaruh nyata pada selang } \\
\text { kepercayaan } 95 \% \text { dengan nilai signifikan }(\mathrm{Pr}>\mathrm{F}) 0.05(\alpha) \\
\text { tn }=\text { perlakuan tidak berpengaruh nyata pada selang } \\
\text { kepercayaan } 95 \% \text { dengan nilai signifikan }(\mathrm{Pr}>\mathrm{F}) 0.05(\alpha)\end{array}$} \\
\hline
\end{tabular}


penambahan mikoriza terhadap berat kering total semai mahoni disajikan pada Tabel 3.

Perlakuan komposisi pot organik koran:kompos perbandingan 3:2 dengan penambahan mikoriza menghasilkan respon pertambahan tinggi semai (Tabel 2) dan berat kering total semai (Tabel 3) terbaik dibandingkan dengan perlakuan lain. Hal ini sesuai dengan hasil analisis kandungan unsur C-organik, $\mathrm{N}$ total, P-total, P-tersedia dan $\mathrm{C} / \mathrm{N}$ rasio berbagai komposisi pot organik (Tabel 4) yang menunjukkan bahwa komposisi pot organik koran:kompos dengan perbandingan 3:2 mengandung unsur hara C-organik sangat tinggi, $\mathrm{N}$-total tinggi, $\mathrm{P}$-total sangat tinggi, dan $\mathrm{P}$ tersedia sangat tinggi. Menurut Eviati dan Sulaeman (2009) kandungan unsur $\mathrm{C}$ tergolong sangat tinggi jika $>5 \%$, kandungan unsur $\mathrm{N}$ tergolong tinggi pada rentang $0.51-0.75 \%$, kandungan P-total sangat tinggi jika $>60$ ppm, dan kandungan P-tersedia sangat tinggi jika $>15$ ppm. Komposisi pot organik koran:kompos dengan perbandingan 3:2 mengandung unsur hara C-organik sebesar $7.74 \%$, kandungan $\mathrm{N}$-total sebesar $0.60 \%$, kandungan P-total sebesar 227.03 ppm, dan kandungan P-tersedia sebesar $154.78 \mathrm{ppm}$.

Hasil analisis kandungan unsur hara pada berbagai komposisi pot organik (Tabel 4.) menunjukkan bahwa kandungan unsur P-total paling tinggi terdapat pada

Tabel 3 Uji Duncan pengaruh interaksi komposisi pot organik dan penambahan mikoriza terhadap berat kering total (BKT) semai mahoni

\begin{tabular}{lcc}
\hline \multicolumn{1}{c}{ Perlakuan } & $\begin{array}{c}\text { Rata-rata } \\
\text { BKT }\end{array}$ & $\begin{array}{c}\% \\
\text { peningkatan }\end{array}$ \\
\hline $\begin{array}{l}\text { Koran 100\% } \\
\text { (tanpa mikoriza) }\end{array}$ & $14.55 \mathrm{c}$ & 0.00 \\
$\begin{array}{l}\text { Koran } 100 \% \\
\text { (dengan mikoriza) }\end{array}$ & $14.96 \mathrm{cb}$ & 2.82 \\
$\begin{array}{l}\text { Koran:Kompos }=3: 2 \\
\text { (tanpa mikoriza) }\end{array}$ & $15.27 \mathrm{cb}$ & 4.95 \\
$\begin{array}{l}\text { Koran:Kompos }=3: 2 \\
\text { (dengan mikoriza) }\end{array}$ & $16.75 \mathrm{a}$ & 15.12 \\
$\begin{array}{l}\text { Koran:Arang }=3: 2 \\
\text { (tanpa mikoriza) }\end{array}$ & $15.12 \mathrm{cb}$ & 3.92 \\
$\begin{array}{l}\text { Koran:Arang }=3: 2 \\
\text { (dengan mikoriza) }\end{array}$ & $15.28 \mathrm{cb}$ & 5.02 \\
$\begin{array}{l}\text { Koran:Kompos:Arang } \\
=1: 1: 1 \text { (tanpa }\end{array}$ & & \\
mikoriza) & $15.23 \mathrm{cb}$ & 4.67 \\
$\begin{array}{l}\text { Koran:Kompos:Arang } \\
\text { 1:1:1 (dengan } \\
\text { mikoriza) }\end{array}$ & & \\
\hline
\end{tabular}

Keterangan: Angka yang diikuti oleh huruf yang sama menunjukkan perlakuan tidak berbeda nyata pada selang kepercayaan $95 \%$. perlakuan koran:arang dengan perbandingan 3:2 yaitu sebesar 1232.43 ppm. Kandungan unsur P-tersedia paling tinggi terdapat pada perlakuan koran:kompos:arang dengan perbandingan 1:1:1 yaitu sebesar $162.45 \mathrm{ppm}$. Berdasarkan hasil pengukuran ratarata pertambahan tinggi dan berat kering total semai mahoni diketahui bahwa perlakuan yang menghasilkan rata-rata pertambahan tinggi dan berat kering total paling bagus yaitu perlakuan koran:kompos dengan perbandingan 3:2 yang diinokulasi mikoriza meskipun kandungan unsur $\mathrm{P}$ pada perlakuan ini lebih rendah dibandingkan dengan perlakuan komposisi pot koran:arang dengan perbandingan 3:2 maupun koran: kompos:arang dengan perbandingan $1: 1: 1$.

Penambahan mikoriza pada perlakuan komposisi koran:kompos dengan perbandingan 3:2 menghasilkan pertambahan tinggi dan berat kering total yang lebih bagus dibandingkan dengan perlakuan komposisi pot koran:arang dengan perbandingan 3:2 maupun koran:kompos:arang dengan perbandingan 1:1:1. Hal ini disebabkan oleh karakteristik FMA yang perkembangannya akan terhambat pada kandungan unsur P yang tinggi. Menurut Budi et al. (2015) kelebihan unsur $\mathrm{P}$ akan mengurangi kolonisasi dan produksi spora mikoriza. Menurut Muis et al. (2013) kondisi media yang mengandung unsur $\mathrm{P}$ terlalu tinggi tidak bagus untuk

Tabel 2 Uji Duncan pengaruh interaksi komposisi pot organik dan penambahan mikoriza terhadap pertambahan tinggi $(\Delta \mathrm{t})$ semai mahoni

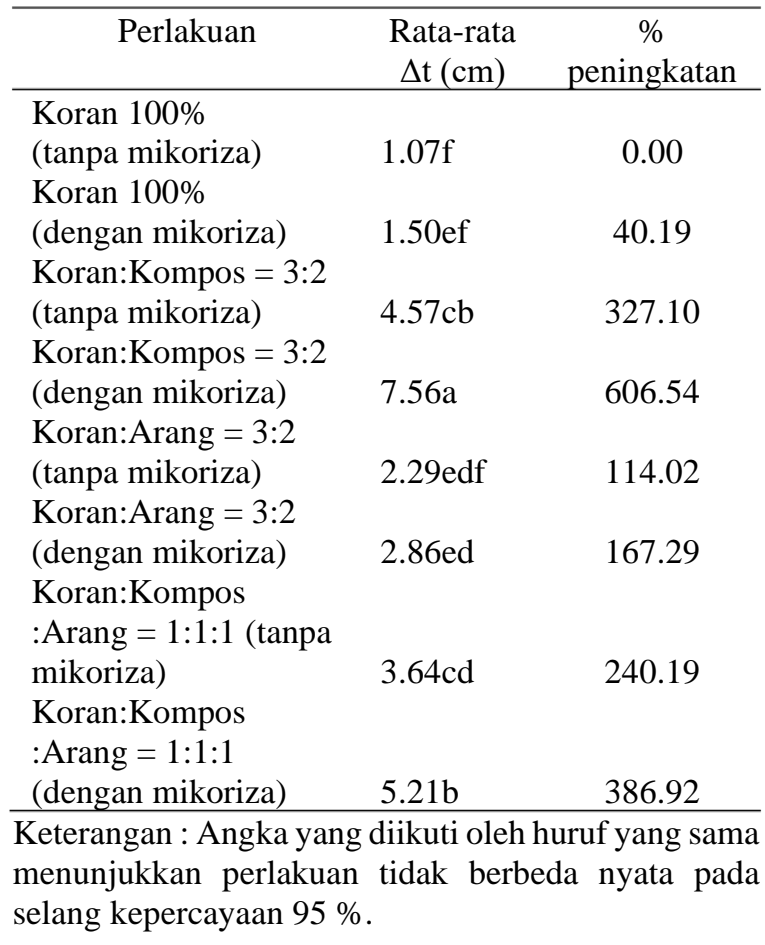

Tabel 4 Kandungan unsur C-organik, N-total, P-total, P-tersedia dan C/N rasio berbagai komposisi pot organik

\begin{tabular}{llrrrrr}
\hline No & \multicolumn{1}{c}{ Perlakuan } & $\begin{array}{c}\text { P-total } \\
(\mathrm{ppm})\end{array}$ & $\begin{array}{c}\text { P-tersedia } \\
(\mathrm{ppm})\end{array}$ & $\begin{array}{r}\text { C-organik } \\
(\%)\end{array}$ & $\begin{array}{r}\text { N-total } \\
(\%)\end{array}$ & C/N rasio \\
\hline 1 & Koran 100\% & 320.00 & 30.87 & 7.19 & 0.43 & 16.72 \\
2 & Koran:Kompos = 3:2 & 227.03 & 154.78 & 7.74 & 0.60 & 12.9 \\
3 & Koran:Arang = 3:2 & 1232.43 & 160.65 & 5.37 & 0.43 & 12.49 \\
4 & Koran:Kompos:Arang = 1:1:1 & 854.05 & 162.45 & 7.66 & 0.64 & 11.97 \\
\hline
\end{tabular}


perkembangan mikoriza karena menghambat pertumbuhan hifa, perkecambahan spora, dan inisiasi kolonisasi akar.Perkembangan FMA yang terhambat pada kondisi kandungan unsur $\mathrm{P}$ yang tinggi pada perlakuan komposisi pot koran:arang dengan perbandingan 3:2 maupun koran: kompos:arang dengan perbandingan 1:1:1 tersebut menyebabkan fungsi mikoriza yang membantu penyerapan unsur hara bagi pertumbuhan tanaman menjadi terhambat juga. Hal ini berarti pot organik dan media tanam harus mengandung unsur P yang cukup agar mikoriza dapat menyerapnya sehingga semai dapat tumbuh dengan baik.

Menurut Simanungkalit et al. (2006) mikoriza dapat membantu penyerapan unsur hara yang dibutuhkan oleh pertumbuhan tanaman. Kompos yang digunakan sebagai bahan pembuatan pot organik mengandung N-total sebesar $1.29 \%, \mathrm{P}_{2} \mathrm{O}_{5} 0.92 \%$, dan C-organik sebesar 15.99\%. Menurut Yuniwati et al. (2012) kompos mengandung unsur hara makro dan mikro lengkap yang dibutuhkan oleh tanaman. Adanya penambahan mikoriza pada perlakuan komposisi koran: kompos dengan perbandingan 3:2 menyebabkan peningkatan jumlah unsur hara yang diserap oleh tanaman. Hal ini yang menyebabkan komposisi pot organik koran:kompos dengan perbandingan 3:2 yang diinokulasi mikoriza menghasilkan pertambahan tinggi dan berat kering total semai mahoni paling bagus dibandingkan dengan perlakuan lain.

Nilai $\mathrm{C} / \mathrm{N}$ rasio menunjukkan kemudahan suatu bahan untuk terdekomposisi. Menurut Pandebesie dan Rayuanti (2013) nilai C/N rasio yang tinggi dapat memperlambat proses dekomposisi. Menurut Eviati dan Sulaeman (2009) nilai C/N rasio tergolong sedang pada rentang 11-15 dan tergolong tinggi pada rentang 16-25. Nilai $\mathrm{C} / \mathrm{N}$ rasio komposisi pot organik koran:kompos dengan perbandingan 3:2, koran:arang dengan perbandingan $3: 2$, dan koran: kompos:arang dengan perbandingan 1:1:1 memiliki nilai $\mathrm{C} / \mathrm{N}$ rasio yang sedang. Komposisi pot organik koran $100 \%$ mengandung nilai $\mathrm{C} / \mathrm{N}$ rasio yang tinggi. Hal ini berarti komposisi pot organik koran:kompos dengan perbandingan 3:2, koran:arang dengan perbandingan 3:2, dan koran:kompos: arang dengan perbandingan 1:1:1 lebih mudah terdekomposisi dibandingkan dengan komposisi pot organik koran $100 \%$.

Nilai $\mathrm{C} / \mathrm{N}$ rasio juga menunjukkan ketersediaan unsur hara pada pot organik. Menurut Surtinah (2013) nilai $\mathrm{C} / \mathrm{N}$ rasio yang tinggi menunjukkan bahwa kandungan unsur hara yang tersedia untuk tanaman jumlahnya sedikit sedangkan nilai $\mathrm{C} / \mathrm{N}$ rasio yang sedang menunjukkan ketersediaan unsur hara yang cukup tinggi bagi tanaman. Hal ini berarti komposisi pot organik koran:kompos dengan perbandingan 3:2, koran:arang dengan perbandingan 3:2, dan koran: kompos:arang dengan perbandingan 1:1:1 memiliki unsur hara yang cukup tinggi bagi pertumbuhan semai mahoni.

\section{Pengaruh Komposisi Pot Organik}

Hasil analisis sidik ragam pengaruh komposisi pot organik terhadap pertumbuhan semai mahoni disajikan pada Tabel 5. Berdasarkan analisis sidik ragam tersebut menunjukkan bahwa perlakuan tunggal komposisi pot organik berpengaruh nyata terhadap parameter pertambahan diameter semai mahoni. Hasil uji Duncan pengaruh komposisi pot organik terhadap pertambahan diameter semai mahoni disajikan pada Tabel 6.

Uji Duncan pengaruh komposisi pot organik terhadap pertambahan diameter semai mahoni pada Tabel 6 menunjukkan bahwa perlakuan komposisi pot organik koran:kompos dengan perbandingan 3:2 menghasilkan respon pertambahan diameter terbaik yaitu dengan rata-rata pertambahan diameter $2.61 \mathrm{~cm}$ dan persen peningkatan sebesar $81.74 \%$ dibandingkan dengan kontrol (koran 100\%). Hal ini disebabkan bahan baku kompos mengandung unsur hara yang dibutuhkan oleh semai mahoni. Kompos dapat meningkatkan pertumbuhan tanaman karena kompos dapat membantu meningkatkan kesuburan tanah dan merangsang pertumbuhan akar (Wasis dan Fathia 2010); dan dapat meningkatkan kandungan bahan organik tanah sehingga mempertahankan dan menambah kesuburan tanah (Simanungkalit et al. 2006).

Penggunaan arang tempurung kelapa sebagai bahan baku pembuatan pot organik menghasilkan pertumbuhan semai mahoni yang kurang bagus dibandingkan dengan bahan baku kompos. Menurut Suhartana (2006) arang tempurung kelapa merupakan salah satu arang aktif yang mempunyai daya serap atau adsorpsi yang tinggi terhadap larutan atau uap. Arang tempurung kelapa ini dapat membantu penyerapan unsur hara tetapi ketersediaan unsur haranya lebih rendah dibandingkan kompos sehingga pertumbuhan semai mahoni lebih

Tabel 5 Hasil analisis sidik ragam pengaruh komposisi pot organik terhadap pertambahan diameter dan $\%$ kolonisasi mikoriza

\begin{tabular}{|c|c|}
\hline Parameter & $\begin{array}{l}\text { Hasil analisis sidik } \\
\text { ragam }\end{array}$ \\
\hline $\begin{array}{l}\text { Diameter } \\
\text { \% Kolonisasi Mikoriza }\end{array}$ & $\begin{array}{c}<.0001^{*} \\
0.1086 \mathrm{tn}\end{array}$ \\
\hline
\end{tabular}

\section{Keterangan :}

Angka-angka dalam tabel adalah nilai signifikan. * $=$ perlakuan berpengaruh nyata pada selang kepercayaan $95 \%$ dengan nilai signifikan $(\operatorname{Pr}>\mathrm{F})$ $0,05(\alpha)$. tn $=$ perlakuan tidak berpengaruh nyata pada selang kepercayaan $95 \%$ dengan nilai signifikan $(\operatorname{Pr}>F) 0,05(\alpha)$

Tabel 6 Uji Duncan pengaruh komposisi pot organik terhadap pertambahan diameter $(\Delta \mathrm{d})$ semai mahoni

\begin{tabular}{lcr}
\hline \multicolumn{1}{c}{ Perlakuan } & $\begin{array}{c}\text { Rata-rata } \\
\Delta \mathrm{d}(\mathrm{cm})\end{array}$ & $\begin{array}{c}\% \\
\text { peningkatan }\end{array}$ \\
\hline Koran $100 \%$ & $1.44 \mathrm{c}$ & 0.00 \\
Koran:Kompos & $2.61 \mathrm{a}$ & 81.74 \\
$=3: 2$ & & \\
Koran:Arang $=3: 2$ & $1.74 \mathrm{~b}$ & 21.29 \\
Koran:Kompos & $2.01 \mathrm{~b}$ & 39.79 \\
:Arang = 1:1:1 & & \\
\hline
\end{tabular}

Keterangan : Angka yang diikuti oleh huruf yang sama menunjukkan perlakuan tidak berbeda nyata pada selang kepercayaan $95 \%$. 
bagus pada pot organik dengan bahan kompos dibandingkan dengan arang tempurung kelapa.

\section{Pengaruh Penambahan Mikoriza}

Hasil analisis sidik ragam pengaruh penambahan mikoriza terhadap pertumbuhan semai mahoni disajikan pada Tabel 7. Berdasarkan analisis sidik ragam tersebut menunjukkan bahwa perlakuan tunggal penambahan mikoriza berpengaruh nyata terhadap pertambahan diameter dan \% kolonisasi mikoriza pada akar semai mahoni. Hasil uji Duncan pengaruh penambahan mikoriza terhadap pertambahan diameter semai mahoni disajikan pada Tabel 8.

Hasil uji Duncan pengaruh penambahan mikoriza terhadap \% kolonisasi mikoriza disajikan pada Tabel 9, Perlakuan penambahan mikoriza menghasilkan respon pertambahan diameter semai disajikan pada Tabel 7, dan $\%$ kolonisasi mikoriza disajikan pada Tabel 8 yang lebih

Tabel 7 Hasil analisis sidik ragam pengaruh penambahan mikoriza terhadap parameter pertumbuhan semai mahoni

\begin{tabular}{lc}
\hline Parameter & $\begin{array}{c}\text { Hasil analisis sidik } \\
\text { ragam }\end{array}$ \\
\hline Diameter & $<.0001^{*}$ \\
$\%$ Kolonisasi Mikoriza & $0.0002^{*}$ \\
\hline
\end{tabular}

Keterangan: Angka-angka dalam tabel adalah nilai signifikan.

* = perlakuan berpengaruh nyata pada selang kepercayaan 95\% dengan nilai signifikan $(\mathrm{Pr}>\mathrm{F})$ $0,05(\alpha)$

tn $=$ perlakuan tidak berpengaruh nyata pada selang kepercayaan 95\% dengan nilai signifikan $(\mathrm{Pr}>\mathrm{F})$ $0,05(\alpha)$

Tabel 8 Uji Duncan pengaruh penambahan mikoriza terhadap pertambahan diameter $(\Delta d)$ semai mahoni

\begin{tabular}{crr}
\hline Perlakuan & $\begin{array}{c}\text { Rata-rata } \\
\Delta \mathrm{d}(\mathrm{cm})\end{array}$ & \multicolumn{2}{c}{$\begin{array}{c}\text { peningkatan } \\
\end{array}$} & $1.71 \mathrm{~b}$ & 0.00 \\
\hline Tanpa Mikoriza & $2.19 \mathrm{a}$ & 28.26 \\
Dengan Mikoriza &
\end{tabular}

Keterangan: Angka yang diikuti oleh huruf yang sama menunjukkan perlakuan tidak berbeda nyata pada selang kepercayaan $95 \%$.

Tabel 9 Uji Duncan pengaruh penambahan mikoriza terhadap persentase kolonisasi mikoriza pada akar semai mahoni

\begin{tabular}{ccr}
\hline Perlakuan & $\begin{array}{c}\text { Rata-rata persentase } \\
\text { kolonisasi mikoriza } \\
(\%)\end{array}$ & $\begin{array}{c}\% \\
\text { peningkatan }\end{array}$ \\
\hline Tanpa & $7 \mathrm{~b}$ & 0.00 \\
$\begin{array}{c}\text { Mikoriza } \\
\text { Dengan }\end{array}$ & $29 \mathrm{a}$ & 314.28 \\
Mikoriza & & \\
\hline
\end{tabular}

Keterangan: Angka yang diikuti oleh huruf yang sama menunjukkan perlakuan tidak berbeda nyata pada selang kepercayaan $95 \%$. baik dibandingkan dengan perlakuan tanpa penambahan mikoriza. Hal ini menunjukkan bahwa penambahan mikoriza pada semai mahoni membentuk simbiosis yang efektif. Hal ini sesuai dengan pernyataan Nusantara et al. (2012) bahwa simbiosis mikoriza dan akar tanaman dikatakan efektif jika menghasilkan pengaruh yang menguntungkan bagi tanaman inang.

Menurut Budi et al. (2015) kolonisasi FMA akan menyebabkan perubahan morfologi dan fisiologi akar dan naiknya laju fotosintat dari daun ke akar sehingga terjadi peningkatan pertumbuhan tanaman secara keseluruhan. Mikoriza berfungsi sebagai pompa dan pipa karena dapat membantu tanaman untuk menyerap unsur hara dan air pada lokasi yang tidak terjangkau oleh rambut akar.

Menurut Simanungkalit et al. (2006) FMA memiliki ciri khas adanya struktur vesikel dan/atau arbuskel. Vesikel merupakan struktur berdinding tipis yang mempunyai bentuk bulat, lonjong, atau tidak teratur. Arbuskel merupakan struktur dalam akar berbentuk seperti pohon yang merupakan percabangan hifa intraradikal setelah hifa cabang menembus dinding sel korteks.

\section{Nisbah Pucuk Akar}

Hasil pengukuran NPA semai mahoni disajikan pada Gambar 1. Menurut Santosa et al. (2013) nisbah pucuk akar (NPA) menunjukkan perbandingan antara kemampuan akar menyerap air dan unsur hara dari tanah dengan proses transpirasi dan luasan fotosintesis pada bagian pucuk tanaman. Gambar 1 menunjukkan bahwa pengaruh perlakuan komposisi bahan baku pot organik menghasilkan nilai nisbah pucuk akar (NPA) rata-rata > 1.5. Nilai NPA terendah terdapat pada perlakuan koran:arang dengan perbandingan 3:2 tanpa inokulasi mikoriza yaitu sebesar 1.963 .

Menurut Santosa et al. (2013) semakin kecil nilai NPA maka bibit semakin siap untuk dipindahkan ke lapangan karena semakin tercukupinya jumlah akar yang akan digunakan untuk menyerap air dan unsur hara yang

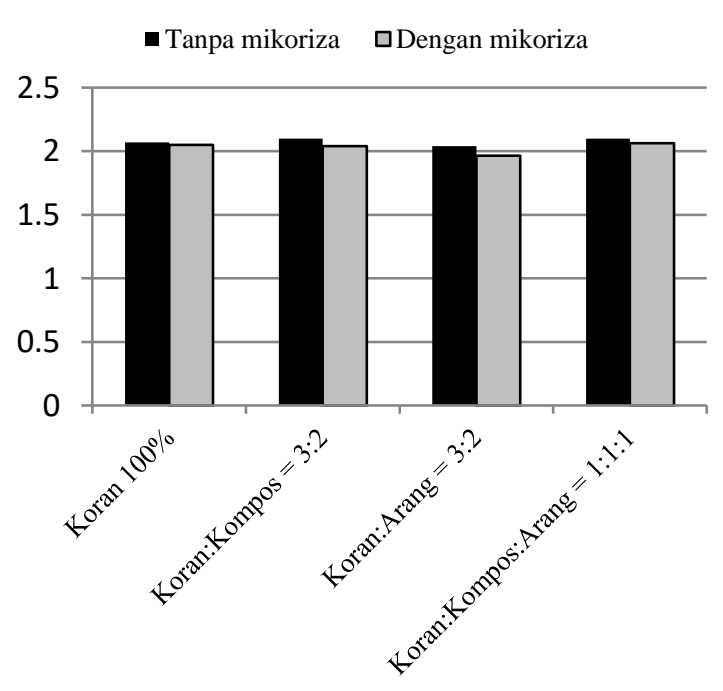

Gambar 1 Diagram nisbah pucuk akar semai mahoni 
akan menunjang pertumbuhan semai di lapang. Semai mahoni yang paling siap ditanam di lapang yang kekurangan air yaitu semai yang diberi perlakuan koran:arang dengan perbandingan 3:2 tanpa inokulasi mikoriza karena tercukupinya jumlah akar yang akan digunakan untuk menyerap air dan unsur hara.

\section{SIMPULAN DAN SARAN}

\section{Simpulan}

Perlakuan interaksi komposisi pot organik dan penambahan mikoriza berpengaruh nyata terhadap tinggi dan berat kering total semai mahoni (S. macrophylla King). Perlakuan tunggal komposisi pot organik berpengaruh nyata terhadap pertambahan diameter semai mahoni (S. macrophylla King). Perlakuan tunggal penambahan mikoriza berpengaruh nyata terhadap pertambahan diameter dan \% kolonisasi mikoriza pada akar semai mahoni (S. macrophylla King). Perlakuan komposisi pot organik koran:kompos perbandingan 3:2 dengan penambahan mikoriza menghasilkan respon pertumbuhan semai mahoni ( $S$. macrophylla King) terbaik selama 16 minggu pengamatan.

\section{Saran}

Perlu diciptakan alat pencetak pot organik mekanis agar pencetakan pot organik lebih praktis. Perlu pengujian pot organik di lapangan untuk mengetahui respon pertumbuhan bibit yang ditanam di lapang.

\section{DAFTAR PUSTAKA}

Budi SW, Sukendro A, Karlinasari L. 2012. Penggunaan pot berbahan dasar organik untuk pembibitan Gmelina arborea roxb. di persemaian. J. Agron. Indonesia 40(3):239-245.

Budi SW, Purwanti SI, Turjaman M. 2015. Fungi mikoriza arbuskula dan arang tempurung kelapa mempercepat pertumbuhan awal bibit Calliandra calothyrsus Meissn di media tanah marginal. Jurnal Silvikultur Tropika. 06(2):114-118.

Eviati, Sulaeman. 2009. Analisis Kimia Tanah, Tanaman, Air, dan Pupuk. Prasetyo BH, Santoso
D, Retno L, editor. Bogor (ID): Balai Penelitian Tanah.Khoiroh Y, Harijati N, dan Mastuti R. 2014. Pertumbuhan serta hubungan kerapatan stomata dan berat umbi pada Amorphophallus muelleri Blume dan Amorphophallus variabilis Blume. Jurnal Biotropika. 2(5): 249-253.

Kementerian Perencanaan Pembangunan Nasional. 2014. Rancangan Awal Rencana Pembangunan Jangka Menengah Nasional 2015-2019. Jakarta (ID): Kementerian Perencanaan Pembangunan Nasional.

Muis A, Indradewa D, Widada J. 2013. Pengaruh inokulasi mikoriza arbuskula terhadap pertumbuhan dan hasil kedelai (Glycine max (L.) Merrill) pada berbagai interval penyiraman. Vegetalika. 2(2): 7-20.

Nusantara AD, Bertham RYH, Mansur HI. 2012. Bekerja dengan Fungi Mikoriza Arbuskula. Bogor (ID): SEAMEO BIOTROP.

Santosa AC, Harwati T, Siswadi. 2013. Pengaruh pemberian mikoriza arbuskula dan pupuk organik terhadap pertumbuhan bibit jati putih (Gmelina arborea Roxb.). Jurnal Inovasi Pertanian. 12(2): 53-66.

Simanungkalit RDM, Suriadikarta DA, Saraswati R, Setyorini D, Hartatik W. 2006. Pupuk Organik Dan Pupuk Hayati. Bogor(ID): Balai Besar Litbang Sumberdaya Lahan Pertanian Badan Penelitian dan Pengembangan Pertanian

Suhartana. 2006. Pemanfaatan tempurung kelapa sebagai bahan baku arang aktif dan aplikasinya untuk penjernihan air sumur di Desa Belor Kecamatan Ngaringan Kabupaten Grobogan. Berkala Fisika. 9(3): 151-156.

Surtinah. 2013. Pengujian kandungan unsur hara dalam kompos yang berasal dari serasah tanaman jagung manis (Zea mays saccharata). Jurnal Ilmiah Pertanian. 11(1): 11-25.

Wasis B, Fathia N. 2011. Pertumbuhan semai gmelina dengan berbagai dosis pupuk kompos pada media tanah bekas tambang emas. Jurnal Manajemen Hutan Tropika. 17(1): 29-33.

Yuniwati M, Iskarima F, Padulemba A. 2012. Optimasi kondisi proses pembuatan kompos dari sampah organik dengan cara fermentasi menggunakan EM4. Jurnal Teknologi. 5(2): 172-181. 